\title{
A Multi-element Microstrip Antenna for LTE Bands, Wi-Fi and WiMAX Application in Femtocell Network
}

\author{
Zakaria Er-Reguig, Hassan Ammor \\ Research Team in Smart Communications, E3S Research Center, Mohammadia \\ School of Engineering, University Mohammed V in Rabat, Morocco
}

\begin{tabular}{l} 
Article Info \\
\hline Article history: \\
Received Aug 17, 2017 \\
Revised Jan 22, 2018 \\
Accepted May 4, 2018 \\
\hline
\end{tabular}

Keyword:

Femtocell

LTE Bands

Microstrip antenna

Slotted antenna

Three-element

Ultra dense network

Wi-Fi

WiMAX

\section{Corresponding Author:}

Zakaria ER-REGUIG,

Research Team on Smart Communications,

Research Center E3S, Mohammadia School of Engineering,

Avenue Ibn Sina B.P 765, Agdal-Rabat, Morocco.

Email: ZakariaErreguig@ research.emi.ac.ma
Copyright (C) 2018 Institute of Advanced Engineering and Science. All rights reserved.

\section{INTRODUCTION}

We believe that the densification of the network by using FemtoCells represent a commercially attractive solution to extend cellular coverage and enhance indoor network capacity in future 5G networks. FemtoCell is a miniature BS that operates in indoor environments and is envisioned to be useful for coverage enhancement and it would be an affordable solution to extend outdoor. It offers an excellent coverage in indoor areas and enhances the capability of the network by bypassing some of the data to a wired connection. A FemtoCell can be assimilated to a Small Office/Home Office (SOHO) network router that can be easy and simple to set up in offices and houses. Moreover, it is generally approved that increasing the number of cells with lesser radii will be a decisive factor in the next generation of cellular system (i.e. $5 \mathrm{G}$ ) to increase the network capacity by providing required data rates [1]. These can be classified as "network densification", Issued by coverage densification and spectrum aggregation. Coverage densification is reached by improving multiple antennas at the FemtoCell Networks and extending the density of FemtoCell networks in a specified area. Recent research papers predict that small cells are the key technology to achieve 5G obligations [1], [2]. To meet the explosive growth of wireless data traffic and to satisfy the needs of $5 \mathrm{G}$, where there is an anticipated 10,000 times more wireless data traffic and an increase in capacity by 2030 [3], original approaches and novel technologies are necessary. For that, antennas with multiple elements are seen as essential technologies in the emergence of the next generation of cellular wireless technologies (5G). 
Antenna with multiple elements in FemtoCell scenario sectorizes spatially the coverage area into multi-sections and each of the elements takes the same portion of the desired region. $120^{\circ}$ is assigned as the coverage angle for each of the three antenna elements, to maximize the spectral efficiency (SE) and to deal with the relentless demand for increased data rates [4], [5]. The planar microstrip patch antenna is widely used in the modern wireless communication systems for their attractive advantages, specifically massproduction facility, simple structural design, compact size, low profile, w weight, constant gain, and stable radiation patterns [6]. Because of the attractive characteristics, microstrip line-fed antenna is widely used in appearing Small cell applications, and day by day research movement is increased focus on them.

In this paper, a patch antenna in microstrip technology is designed and fabricated for coverage enhancement of FemtoCell network with the use of multiple elements antennas (Figure 1). The development and analysis of the initial mode is computer-generated in a Three-element FemtoCell network like assembly. The design process outcomes, by making controllable beam directions in FemtoCell application. The continuity of this article is structured as follows: Antenna design in part two, results and discussion in part three, array arrangement in FemtoCell in part four and conclusion in part five.

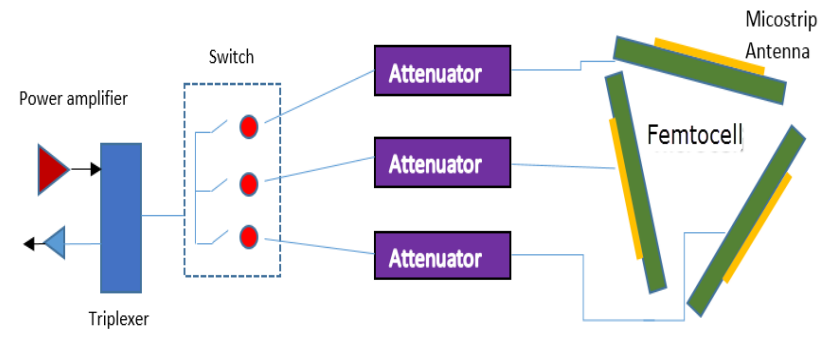

Figure 1. Multi-element antenna configuration in Femtocell (microstrip antenna)

\section{ANTENNA DESIGN}

The FemtoCell box has an enclosed area with limited space and accessibility for RF Circuits and antenna. Therefore, only specific types of antennas can be used for FemtoCell architecture. Actually, antennas with microstrip technology can fit with these requirements. As they are easy fabricated, lightweight and have low assembly cost. However, the process of designing a microstrip antenna is not always an easy task because the microstrip technology has many handicaps which must be taken into consideration in the preliminary phase of conception, for example, narrow bandwidth, small gain and low radiation pattern. Since the region of interest is indoor (about 1 to $10 \mathrm{~m}$ ), multi-element antennas with microstrip technology for FemtoCell network is an attractive solution for the above type of application. Initially, the antennal structure was a simple monopole patch antenna, through a parametric optimization process by adding slots and trimming edges we got to the finale structure as shown in Figure 2. The antennas with microstrip technology are fabricated with various shapes and the most commonly designed antennas are: E, H, I, U, S slotted patch antennas [7-9], etc....

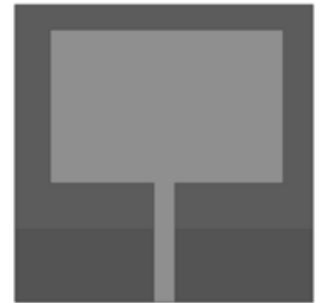

Antenna 1

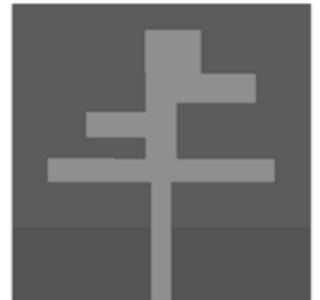

Antenna 2

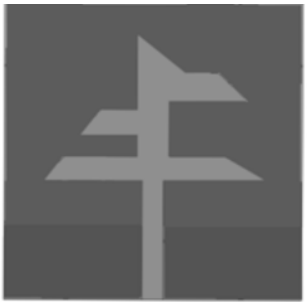

Antenna 3

Figure 2. Evolution of the proposed antenna modeling

Here, the basic antenna was a classic rectangular patch that has undergone numerous changes in order to optimize the limitation of narrow bandwidth of a typical rectangular patch antenna by Bhatia [10] who specifies the width of the basic patch antenna as: 


$$
\mathrm{W}=\frac{C}{2 \mathrm{f}_{\mathrm{r}} \sqrt{\frac{\varepsilon_{\mathrm{r}+1}}{2}}}
$$

Where $f_{r}$ and $e_{r}$ are frequency of operation and relative permittivity, one-to-one. Then, the effective permittivity is given approximately by Gilb [11] in this formula:

$$
\varepsilon_{\mathrm{reff}}=\frac{\varepsilon_{\mathrm{r}}+1}{2}+\frac{\varepsilon_{\mathrm{r}}-1}{2}\left(1+12 \frac{\mathrm{h}}{\mathrm{W}}\right)^{-\frac{1}{2}}
$$

Where $\mathrm{h}$ is the height or the thickness of the dielectric substrate used for the model of the studied antenna. [12] gives the real dimension of the microstrip patch length as:

$$
\mathrm{L}=\frac{c}{2 \mathrm{f}_{\mathrm{r}} \sqrt{\varepsilon_{\mathrm{r}}}}-2 \Delta \mathrm{L}
$$

Where $\Delta \mathrm{L}$ is the addition of the patch distance on the edges of the microstrip antenna that is set by Hammerstad [13] as:

$$
\Delta \mathrm{L}=0.412 \mathrm{~h} \frac{\left(\varepsilon_{\mathrm{reff}}+0.3\right)\left(\frac{w}{h}+0.264\right)}{\left(\varepsilon_{\mathrm{reff}}-0.258\right)\left(\frac{w}{h}+0.8\right)}
$$

The ground plane dimensions can be considered as:

$$
\left\{\begin{array}{l}
\mathrm{L}_{g}=6 \mathrm{~h}+\mathrm{L} \\
\mathrm{W}_{g}=6 \mathrm{~h}+\mathrm{W}
\end{array}\right.
$$

The Microstrip patch antenna in Figure 3 consists of three layers: ground, substrate and patch.
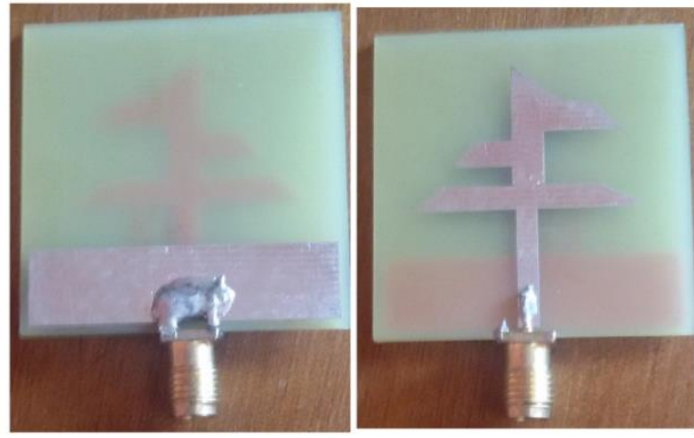

Figure 3. Image of the realized antenna

The dielectric substrate considered for the design of the proposed antenna is FR4_Epoxy with a thickness of $1.58 \mathrm{~mm}$ and a dielectric constant $\varepsilon \mathrm{r}=4.4$. It is generally known in the scientific committee that the use of substrates with a low thickness and dielectric constant makes it possible to reduce the size of the antennas [14]. It is widely known that the FR4 substrate is a lossy substrate and reveals poor performance with the increase in frequency. However, several research papers have successfully implanted the FR4 substrate in higher frequency bands (above $2 \mathrm{GHz}$ ) by miniaturizing the size of the antenna structure to reduce the effect of the substrate on the signal loss [15],[16]. The Antenna feed is performed by a microstrip line; this adapter is required to have $50 \Omega$ at the input of the microstrip antenna and to route the electromagnetics waves from the source to the antenna without causing reflections. The dimensions of the substrate are taken as $35 \times 35 \times 1.58 \mathrm{~mm}^{3}$ and the size of the partial ground plane is $8.75 \times 35 \mathrm{~mm}^{2}$. Figure 4 shows the top and bottom layers of the final geometry of the studied antenna. The optimal antenna parameters are summarized in Table 1. 


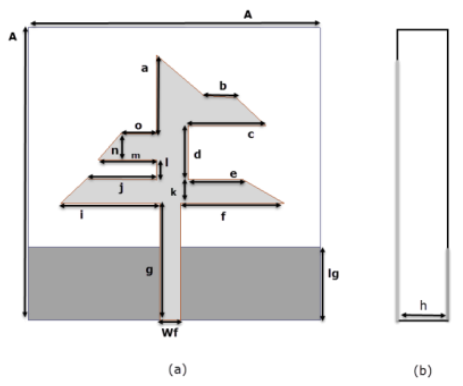

Figure 4. The geometry of the proposed antenna (not to scale),

(a) Top view, (b) Side view
Table 1. Optimal Parameters of the Proposed Antenna

\begin{tabular}{cc}
\hline Parameter & Value $(\mathrm{mm})$ \\
\hline$A$ & 35 \\
$h$ & 1.58 \\
$a$ & 9.4 \\
$b$ & 3.8 \\
$c$ & 9.3 \\
$e, d$ & 6.5 \\
$f$ & 12.4 \\
$g$ & 14 \\
$i$ & 11.9 \\
$j$ & 8.3 \\
$k$ & 2.8 \\
$l$ & 2.4 \\
$m$ & 7 \\
$n$ & 3.1 \\
$o$ & 4.3 \\
$w f$ & 2.5 \\
$l g$ & 8.75 \\
\hline
\end{tabular}

\section{RESULTS AND DISCUSSION}

The $S_{11}$ parameter versus frequency is shown in Figure 5. The first point is to estimate the effect of the ground plane on the widening of the bandwidth, a partial ground plane allowed us to expand the bandwidth, narrow with a full ground plane. The partial ground plane shows better return loss compared to the full ground plane.

VSWR and the $S_{11}$-Parameter can be used mutually to determine the matching of an antenna, The plot of VSWR against frequency shows that it is $<2$ for the operational band of interest as shown in Figure 6 . Figure 7 specifies the different values of the S11-Parameter for our proposed antenna model. It was established that the antenna resonates in the desired frequency band as shown in Figure 6. Indeed, for $\left|S_{11}\right|<-$ $10 \mathrm{~dB}$ : the band ranges from $1.88 \mathrm{GHz}$ to $3.6 \mathrm{GHz}$ with two resonant frequencies at $2.4 \mathrm{GHz}$ and $3.5 \mathrm{GHz}$. The bandwidth is approximately $1700 \mathrm{MHz}$ which usually suitable for many LTE bands $\{1,3,7 \ldots 38,40\}$ broadly deployed in European, South American, Asian, and African countries [15, 16], Wi-Fi $(2.4 \mathrm{GHz})$, and WiMAX technology $(3.5 \mathrm{GHz})$ as described in Table 2.

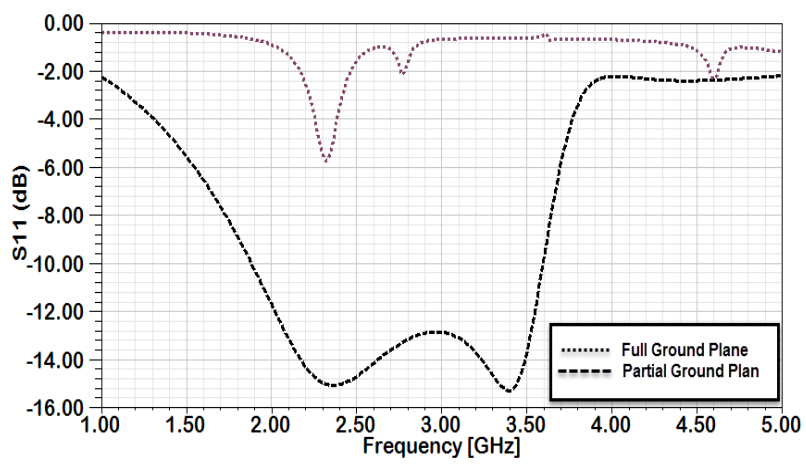

Figure 5. Comparison between the reflection coefficients $\mathrm{S}_{11}$ against frequency
Table 2. Current Major Spectrum Allocations for LTE, Wi-Fi and WiMAX Worldwide

\begin{tabular}{ccc}
\hline Standard & $\begin{array}{c}\text { Frequency } \\
\text { Band (MHz) }\end{array}$ & World deployment \\
\hline LTE Band 1 & $1920-2170$ & China, Japan, EU \\
LTE Band 2 & $1850-1990$ & North/South America \\
LTE Band 7 & $2500-2690$ & North/South \\
& & America, Africa \\
LTE Band 33 & $1900-1920$ & - \\
LTE Band 34 & $2010-2025$ & China \\
LTE Band 35 & $1850-1910$ & - \\
LTE Band 36 & $1930-1990$ & - \\
LTE Band 37 & $1910-1930$ & - \\
LTE Band 38 & $2570-2620$ & EU \\
LTE Band 39 & $1880-1920$ & China \\
LTE Band 40 & $2300-2400$ & - \\
LTE Band 41 & $2496-2690$ & China \\
IEEE & $2400-2500$ & Japan, EU, China, \\
802.11b/g/n & & America. \\
(Wi-Fi) & & North/South \\
WiMAX & 2500,3500 & America, EU, Africa, \\
& & Asia, China \\
\hline
\end{tabular}




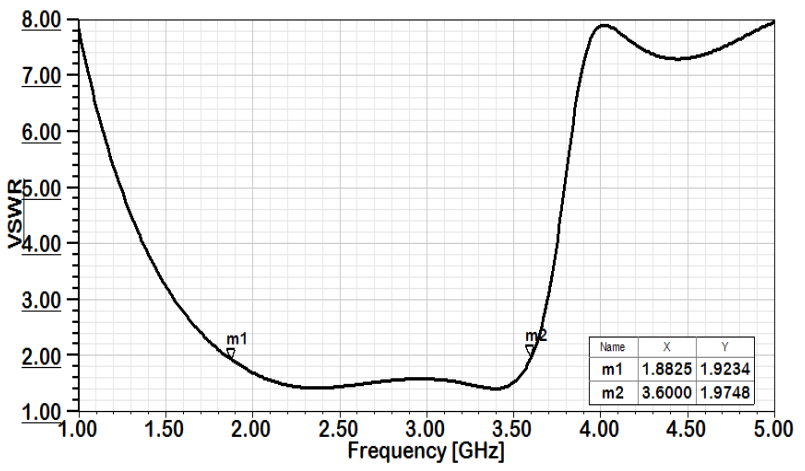

Figure 6: VSWR against frequency

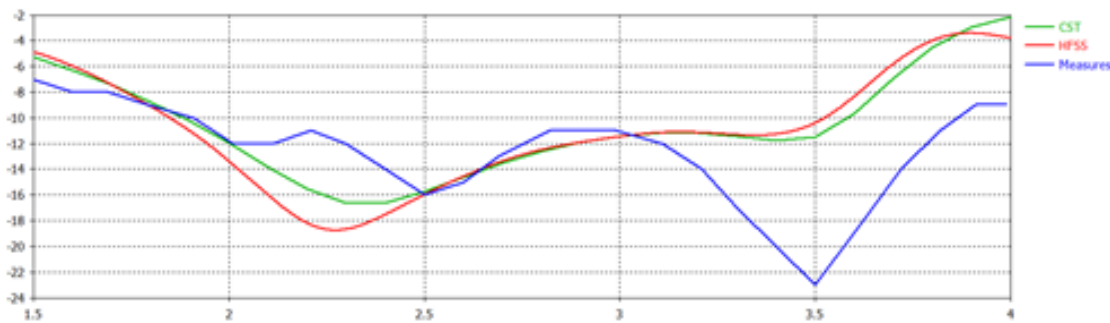

Figure 7: Reflection coefficients $S_{11}$ against frequency

The main characteristics (Operational Bandwidth and Dimensions) of the proposed antenna are compared in Table 3 with some published work results in the literature.

Table 3. Results of All the References and Our Work

\begin{tabular}{ccc} 
Article No. & $\begin{array}{c}\text { Bandwidth } \\
(\mathrm{GHz})\end{array}$ & $\begin{array}{c}\text { Dimensions } \\
\left(\mathrm{mm}^{2}\right)\end{array}$ \\
\hline Ref. [19] & $1.93-3.74$ & $60 \times 50$ \\
Ref. [20] & $1.93-3.6$ & $55 \times 15$ \\
This Work & $1.9-3.6$ & $35 \times 35$ \\
\hline
\end{tabular}

Figures [8-9] shows the field pattern and the gain value of the proposed antenna at two frequencies 2.4GHz and $3.5 \mathrm{GHz}$. The $\mathrm{E}$ ( $\mathrm{x}-\mathrm{y}$ plane) and $\mathrm{H}$ (y-z plane) fields in the figures shows that they have almost good Omni-directional radiation patterns. It may be noted that the typical radiation patterns are dominated at both resonant frequencies: At $2.4 \mathrm{GHz}$ (the inferior resonant frequency), the radiation pattern of the antenna is similar to that of a conventional monopole microstrip antenna in free space, with a so-called 'doughnut' shape. The radiation pattern at the higher functioning frequency becomes more irregular. For both cases, the shape of the partial ground plane affects the radiation patterns. The proposed antenna shows a very good Omni-directional radiation pattern even at lower and higher frequencies, which is required to receive data signals from all directions.
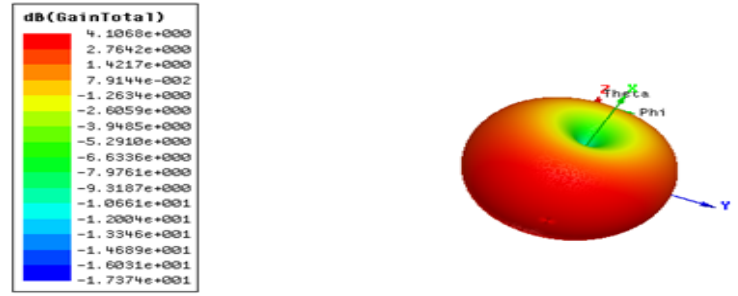

Figure 8: Simulated 3D Radiation pattern at $2.4 \mathrm{GHz}$
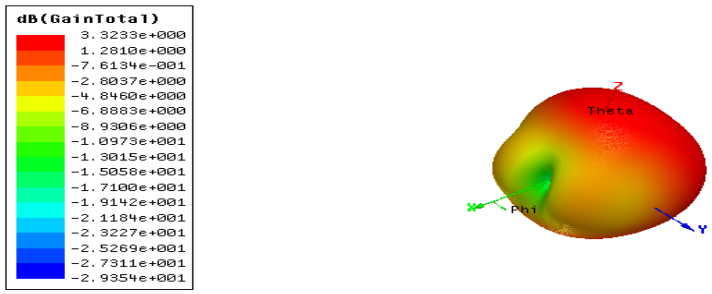

Figure 9: Simulated 3D Radiation pattern at $3.5 \mathrm{GHz}$ 


\section{THREE-ELEMNT ANTENNA CONFIGURATION IN FEMTOCELL SCENARIO}

Femtocell is mostly located in the corner of residential areas or offices where wired connection is available. Thus, in place of considering a conventional omni-directional antennas, a switched based multielement structure is more suitable to enhance the coverage area. To estimate the applicability of this antenna in the FemtoCell scenario, three copies of the previously studied antenna are putted outside a pyramidal box. The three elements are oriented in three directions, placed on the three surfaces area of the pyramidal box as illustrated in Figure 10. Figure 11 illustrates different $\mathrm{S}$ parameters of the studied antenna. Since all three antennas are oriented with an angle of $120^{\circ}$ to each other, the lateral lobes have no major impact on their radiation patterns.

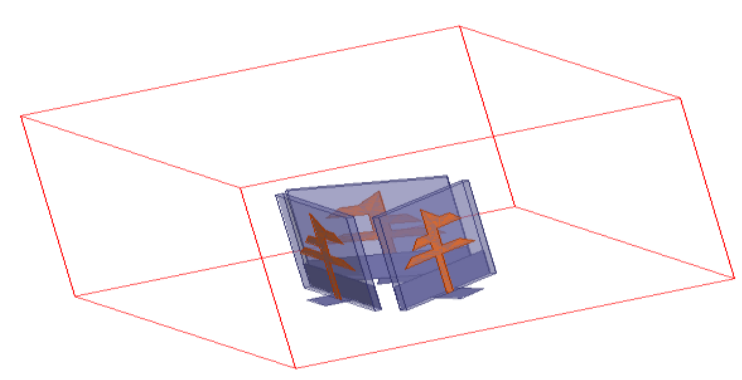

Figure 10. Concept of three-element antenna

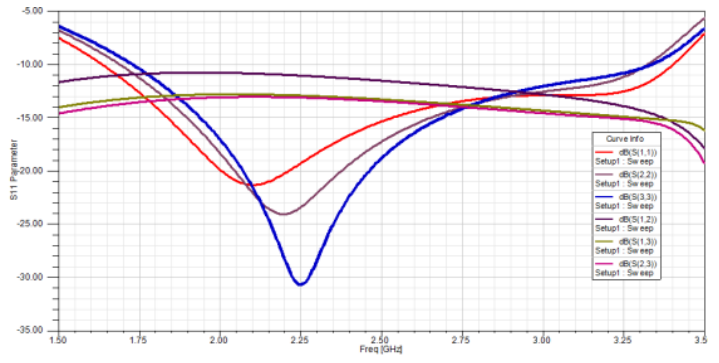

Figure 11. S parameters for multiple combinations of patch antennas

Figure 12 shows the Fairfield gain $(\mathrm{Phi}=0)$ of the Three-element antenna at the frequency $2.4 \mathrm{GHz}$. Thus, by modifying the power amplitude in excitation, the shape of the radiation pattern can be modified, and thereafter, meet the needs of a particular user by minimizing the interference between consumers and providing lower power and better network capacity.

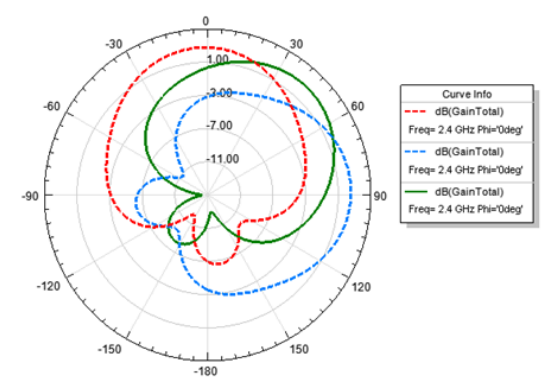

Figure 12. The Radiation Pattern of two microstrip antennas and their resultant beam at $2.4 \mathrm{GHz}$

\section{CONCLUSION}

In this paper, a simple, straightforward and most effective way to increase system capacity and provide coverage optimization by making cells smaller has been presented. The proposed FemtoCell microstrip antenna is simple to design and very compact with a size of $0.22 \lambda(\mathrm{f}=1.9 \mathrm{GHz}) \mathrm{X} 0.22 \lambda(\mathrm{f}=1.9 \mathrm{GHz})$. It 
provides goud impedance matching from $1.9 \mathrm{GHz}$ to $3.5 \mathrm{GHz}$. A low cost dielectric substrate FR4 substrate has been considered in the developpement of the studied antenna. Therefore, it can be deployed in large scale and with a great price-performance ratio

\section{REFERENCES}

[1] J. G. Andrews et al., "What will 5G be?" IEEE J. Sel. Areas Commun., Vol. 32, Nº. 6, pp. 1065-1082, Jun. 2014.

[2] A. Imran, A. Zoha, and A. Abu-Dayya, "Challenges in 5G: How to empower SON with big data for enabling 5G," IEEE Netw., Vol. 28, N. 6, pp. 27-33, Nov. 2014.

[3] T. S. Rappaport, "Special session on mmWave communications," in Proc. IEEE ICC, Budapest, Hungary, Jun. 2013.

[4] V. Chandrasekhar, J. G. Andrews, and A. Gatherer, "FemtoCell networks: a survey," IEEE Communications Magazine, Vol. 46, N. 9, pp. 59-67, 2008.

[5] J.-B. Yan and J. T. Bernhard, "Design of a MIMO dielectric resonator antenna for LTE FemtoCell base stations," IEEE Transactions on Antennas and Propagation, Vol. 60, N. 2, pp. 438-444, 2012.

[6] H. Claussen, L. T.W. Ho, and L. G. Samuel, "An overview of the FemtoCell concept," Bell Labs Tech. J., Vol. 13, $\mathrm{N}^{\circ} .1$, pp. 221-245, 2008.

[7] Yang, F., X. X. Zhang, X. Ye, and Y. Rahmat-Samii, "Wide-band E-shaped patch antennas for wireless communications," IEEE Trans. Antennas Propagat., Vol. 49, N. 7, 1094-1100, July 2001.

[8] Karli, Radouane, and Hassan Ammor. "A SIMPLE AND ORIGINAL DESIGN OF MULTI-BAND MICROSTRIP PATCH ANTENNA FOR WIRELESS COMMUNICATION.", 2013.

[9] [9] R. Chair, C. Mak, K. Lee, K. Luk and A. A. Kishk, "Miniature wideband half U-slot and half E-shaped patch antennas", IEEE Transactions on Antennas and Propagation, Vol. 53, N. 8, pp. 2645-2652, 2005.

[10] P. Bhartia, I. Bahl, R. Garg, and A. Ittipiboon, Microstrip Antenna Design Handbook, Artech House, Norwood, Mass, USA, 2000.

[11] J. P. Gilb and C. A. Balanis, "Pulse distortion on multilayer coupled microstrip lines," IEEE Transactions on Microwave Theory and Techniques, Vol. 37, N. 10, pp. 1620-1628, 1989.

[12] J.-B. Yan and J. T. Bernhard, "Design of a MIMO dielectric resonator antenna for LTE femtocell base stations," IEEE Transactions on Antennas and Propagation, Vol. 60, N. 2, pp. 438-444, 2012.

[13] E. Chang, S. A. Long, and W. F. Richards, "An experimental investigation of electrically thick rectangular microstrip antennas", IEEE Transactions on Antennas and Propagation, Vol. 34, Nº. 6, pp. 767-772, 1986.

[14] Lakrit, S., Ammor, H., Terhzaz, J., Tribak, "A Realization and measurements of a miniature square patch antenna for ultra wideband applications", International Journal of Microwave and Optical Technology, 10 (5), pp. 307-313.

[15] C.-Y. Pan T.-S. Horng W.-S. Chen C.-H. Huang "Dual wideband printed monopole antenna for WLAN/WIMAX applications" IEEE Antenna Wireless Propag. Lett. vol. 6 pp. 149-151 2007.

[16] J. Jung W. Choi J. Choi "A small wideband microstrip-fed monopole antenna" IEEE Microw. Wireless Compon. Lett. vol. 15 no. 10 pp. 703-705 Oct. 2005.

[17] W. S. Pan, C. H. Ma, S. H. Shao, and Y. X. Tang, "A 2.5 GHZ-2.7 GHz unsymmetrical doherty power amplifier with digital predistortion for LTE-advanced applications," Advanced Materials Research, Vol. 760, pp. 546-550, 2013.

[18] E. Dahlman, S. Parkvall, J. Skold, and P. Beming, 3G Evolution: HSPA and LTE for Mobile Broadband, Academic Press, 2010.

[19] Mandal, K., Sarkar, S. and Sarkar, P. P. (2011), Bandwidth enhancement of microstrip antennas by staggering effect. Microw. Opt. Technol. Lett., 53: 2446-2447.

[20] Saini, R. K. and Dwari, S. (2015), CPW-fed broadband circularly polarized rectangular slot antenna with L-shaped feed line and parasitic elements. Microw. Opt. Technol. Lett., 57: 1788-1794. 